\title{
Does Type D Personality Inhibit Benefits of Cardiac Rehabilitation?
}

\author{
Başak Bilir Kaya ${ }^{1}$, (1) Nazmiye Özbilgin²
}

${ }^{1}$ Department of PMR, Ministry of Health Erenkoy Pyhsical Medicine and Rehabilitation Hospital, Istanbul, Turkey

${ }^{2}$ Department of Cardiology, Health Sciences University Siyami Ersek Cardiovascular and Thorasic Surgery Training and Research Hospital, Istanbul, Turkey

\begin{abstract}
Introduction: Cardiovascular diseases are major causes of mortality and morbidity in the world. D type personality is a poor prognostic factor in cardiovascular diseases. Cardiac rehabilitation is known to reduce mortality and morbidity in cardiovascular diseases. The present study aims to investigate whether type D personality inhibits the benefits of cardiac rehabilitation or not. Methods: A single-center, retrospective cohort study was conducted with the evaluation of all CR participants at the University Hospital of Cardiovascular and Thoracic Surgery between 01.02.2017 and 01.02.2019. Study population was the patients who were 18 years and older and completed all 30 sessions of CR program and also completed both pre- and post-tests. Type D personality was assessed with DS14. Quality of life was assessed with SF 36. Functional capacity was assessed with a 6-minute walk test (6MWT). Submaximal cycle ergometer test was performed to evaluate maximum endurance watts. A special CR program was planned for each patient based on the cycle ergometer test peak workload. The primary endpoint was the observation of changes in the Beck Depression Scale, SF-36 scores and the secondary endpoint of the study was the observation of improvement in functional capacity and endurance according to patients' type D personality.

Results: 222 patients enrolled in this study. Among the patients, 37.4\% of them were positive for D type personality. Functional capacity, endurance, quality of life, depression scores were all improved after cardiac rehabilitation $(p<0.01)$. There was no statistically significant difference between $D$ type positive and negative patient groups about the improvements of rehabilitation $(\mathrm{p} \geq 0.05)$.

Discussion and Conclusion: D type personality is associated with inflammation and may increase mortality and morbidity in a cardiovascular disease. Cardiac rehabilitation may improve functional capacity, endurance, quality of life and depression scores independently from D Type personality.

Keywords: Cardiac rehabilitation; type D personality; quality of life.
\end{abstract}

C ardiovascular disease (CVD) is responsible for $17.7 \mathrm{mil}-$ lion deaths in the world ${ }^{[1]}$. According to the European Society of Cardiology (ESC), total of 83.5 million people are living with CVD in Europe ${ }^{[2]}$. CVD has high mortality and morbidity ${ }^{[1,2]}$. One of the most common comorbidi- ties presented with CVD is depression [3]. Also depression is shown to increase mortality of the CVD ${ }^{[4]}$. Type $D$ or Distressed personality means that a patient has high scores of negative affectivity (NA) and social inhibition (SI) in type $D$ personality assessment ${ }^{[5]}$. Type $D$ personality is associ-

Correspondence (İletişim): Başak Bilir Kaya, M.D. Saglik Bakanligi Erenkoy Fizik Tedavi ve Rehabilitasyon Hastanesi, Fiziksel Tip ve Rehabilitasyon Bolumu, Ethem Efendi Cad, Hat Boyu Sok, No: 36, Erenkoy, İstanbul, Turkey Phone (Telefon): +90 5052604649 E-mail (E-posta): basakbilir@gmail.com 
ated with inflammation and can predict mortality in CVD $[6,7]$. Because Type D personality is linked to inflammation, ESC has included Type D personality as an independent risk factor of CVD ${ }^{[8]}$. Type $D$ personality is also associated with low scores of health-related quality of life (HRQoL) in CVD populations ${ }^{[9]}$.

Cardiac rehabilitation (CR) is a multi-component rehabilitation program for cardiac patients designed to decrease mortality and morbidity and also maximize secondary prevention from heart disease ${ }^{[10]}$. CR consists of internationally accepted core components which are nutritional counseling (NC), risk factor modification (RFM), psychosocial management (PM), patient education (PE) and exercise training (ET) ${ }^{[11]}$. A Cochrane review showed that $C R$ reduces mortality and morbidity by $20 \%$ for CVD ${ }^{[12]}$. CR is also shown to decrease depression and increase HRQoL and functional capacity in CVD ${ }^{[13,14]}$.

Our study is focused on these benefits of CR on HRQoL, depression and functional capacity like most of the studies. The new highlight of this study to the literature is that these known benefits of CR are analysed for Type $D$ personality positive and negative patients. The present study aims to investigate the potential effects of Type $D$ personality on $\mathrm{CR}$ related improvement of HRQoL, depression and functional capacity of CVD patients.

\section{Materials and Methods}

A single-center, retrospective cohort study was conducted with the evaluation of all CR participants at the University Hospital of Cardiovascular and Thoracic Surgery between 01.02.2017 and 01.02.2019. The study population was the patients who were 18 years and older and completed all 30 sessions of CR program and also completed both pre- and post-tests. Exclusion criteria were as follows: psychosis, cancer, untreated mental illness and systemic inflammatory disease. This study was approved by a local ethics committee and was performed in accordance with the Declaration of Helsinki. Informed consent was obtained from all the subjects. Patients' demographic data were collected. All patients were outpatient patients of the $C R$ unit.

Type D personality was assessed with DS14 which was also validated for the Turkish population ${ }^{[5,15]}$. DS14 is based on subjective assessment of individuals; 14 substance scale contains questions that measure negative affectivity (NA) and social inhibition (SI) ${ }^{[5]}$. Patients who have high scores from NA subscale are inclined to experience negative emotions (e.g. anxiety and irritability) about situations and the environment they are surrounded. SI score high patients have a tendency to consciously inhibit self-expression during social activities. Reason for this social inhibition is thought to be fear of being rejected and disapproval of society. Subscales' points can be maximum 28 points, and cut-off point for subscales is 10 . Patients with high scores $(\geq 10)$ from both subscales NA and SI are classified as Type $D$ personality positive ${ }^{[5]}$.

Depression was assessed with the Beck Depression Inventory which was also validated for the Turkish population ${ }^{[16,17]}$. Beck Depression Inventory is used to assess patients' depression symptom severity. Beck Depression Inventory contains 21 items, and each item consist of four statements which points to different classes of symptom severity. Patients were asked to answer the questions according to past one week time. A total score was calculated, which shows bigger scores for more depressive symptoms ${ }^{[16]}$.

Quality of life was assessed using SF 36, which is also validated for the Turkish population for various illnesses [18-20]. SF 36 can be summarized with two dimensions which are physical health and mental health of 36 items for measuring eight health concepts: physical functioning, role limitations due to physical health problems, pain, general health perception, vitality, social functioning, role limitations due to emotional problems and general mental health ${ }^{[18]}$.

Functional capacity was assessed using a 6-minute walk test (6MWT). Patients were asked to walk back and forth as much as possible around cones in six minutes on a 30-foot path. They were allowed to slow down or stop if necessary. Talking to the patients while they take the 6MWT was prohibited. Submaximal cycle ergometer test was performed to evaluate endurance. During the test for every 2-minute, watt was increased by 25 watts and the Borg scale was asked to the patient. Assessing the situation of the patient for breath and muscle fatigue according to the patient, the Borg scale was asked during the test. Arterial blood pressure (ABP) was measured at the beginning of the test and every two minutes afterwards, and at the end of the test automatically by the computer system. Electrocardiogram, heart rate and saturation of oxygen were monitored continuously right before, during the test and recovery period. If any lightheadedness, angina, cyanosis, dyspnea, hypoxia, confusion, significant muscle pain (patient declares Borg Scale $\geq 5$ ) occurred, ABP exceeded $180 / 100$ or submaximal heart rate is reached according to Karvonen formula (for patients who does not use beta-blockers), the test was 
ended and the maximum watt was calculated according to the time of the taken test.

A special CR program was planned for each patient based on the cycle ergometer test peak workload. Low-intensity interval training was prescribed for patients with low initial test performance. Exercise program for patients using beta-blockers was given independent of heart rate. All core components of $C R$ were administered according to patients' specific needs. Each patient's CR program was evaluated after 10 sessions and was updated by the physiatrist according to Borg scales assessed by the rehabilitation nurse during the exercise sessions. Each exercise program started with a warm-up and ended with a recovery period, which is also monitored continuously for heart rate, oxygen saturation, $A B P$ and electrocardiogram. All of the patients who attend $C R$ program received NC from the dietician, PC from the psychologist, and patient education according to their special health conditions (e.g. diabetes) from CR nurse. Smokers were guided to the tobacco cessation outpatient clinic. In one week of completion of CR sessions, all the tests were repeated.

The primary endpoint was the observation of changes in Beck Depression Inventory, SF-36 scores and the secondary endpoint of this study was the observation of improvement in functional capacity and endurance according to patients' type $D$ personality.

\section{Statistical Analysis}

NCSS (Number Cruncher Statistical System) 2007 (Kaysville, Utah, USA) program was used for statistical analysis. Descriptive statistical methods (mean, standard deviation, median, frequency, percentage, minimum, maximum) were used when evaluating the study data. The Mann-Whitney $U$ test was used in comparisons between two groups of quantitative variables that did not show Normal distribution. The T-test was used in the in-Group comparisons of quantitative variables with Normal distribution. Wilcoxon signed-ranks test was used for in-Group comparisons of quantitative variables that did not show Normal distribution. Statistical significance was considered $\mathrm{p}<0.05$.

\section{Results}

This study was enrolled in a University Hospital of Cardiovascular and Thoracic Surgery between 01.02.2017 and 01.02.2019. There were a total of 222 patients enrolled in this study. $37.4 \%$ of the 222 patients had Type D personality other demographics and Type D personality charac-
Table 1. Demographics and type D personality characteristics of the patients

\begin{tabular}{|c|c|}
\hline \multicolumn{2}{|l|}{ Age } \\
\hline Min-Max (Median) & $21-81(57)$ \\
\hline Mean \pm SD & $56.44 \pm 10.31$ \\
\hline \multicolumn{2}{|l|}{ Gender } \\
\hline Female & $120(54.1)$ \\
\hline Male & $102(45.9)$ \\
\hline \multicolumn{2}{|l|}{ Diagnosis } \\
\hline Hypertension & $99(44.8)$ \\
\hline Heart failure & $23(10.4)$ \\
\hline Coronary artery disease & $89(40.3)$ \\
\hline Arrhytmia & $10(4.5)$ \\
\hline \multicolumn{2}{|l|}{ DS 14} \\
\hline \multicolumn{2}{|l|}{ Negative affectivity } \\
\hline Min-Max (Median) & $0-26(11)$ \\
\hline Mean \pm SD & $11.09 \pm 6.87$ \\
\hline \multicolumn{2}{|l|}{ Negative affectivity } \\
\hline$<10$ & $98(42.2)$ \\
\hline$\geq 10$ & $134(57.8)$ \\
\hline \multicolumn{2}{|l|}{ Social inhibition } \\
\hline Min-Max (Median) & $1-23(10)$ \\
\hline Mean \pm SD & $10.24 \pm 4.91$ \\
\hline \multicolumn{2}{|l|}{ Social inhibition } \\
\hline$<10$ & $112(48.3)$ \\
\hline$\geq 10$ & $120(51.7)$ \\
\hline \multicolumn{2}{|l|}{ Type D personality } \\
\hline Type D (+) & $83(37.4)$ \\
\hline Type D (-) & $139(62.6)$ \\
\hline
\end{tabular}

teristics of the patients are in Table 1. Patients lost weight after 30 sessions of CR. Before rehabilitation average body mass and body mass index of patients were $80.99 \pm 13.63$ $\mathrm{kg}, 29.80 \pm 4.92$ and after $C R$, it was $79.79 \pm 13.31 \mathrm{~kg}$ and $29.35 \pm 4.60$ respectively $(p \leq 0.01)$. Functional capacity (6MWT) and endurance (Cycle Ergometer Test Maximum Watts) of the patients statistically significantly increased after CR sessions (Table 2). The decrease in the Beck Depression scores was statistically significant after CR (Table 3). Also, the quality of life measures was increased after $C R$ for both physical health and mental health subscales of SF-36 (Table 3). These statistically significant benefits which are body mass, BMI, functional status, endurance, Beck Depression scores and $\mathrm{HRQ}$ oL are investigated for Type $D$ positive patients, and there was no statistically significant difference between the Type $D$ positive and negative patients for these benefits (Table 4). 
Table 2. Evaluation of weight, BMI, endurance and physical funcion before and after cardiac rehabilitaion

\begin{tabular}{|c|c|c|c|c|}
\hline & Before CR & After CR & Difference & Test value; $p$ \\
\hline \multicolumn{5}{|l|}{ Weight (kg) } \\
\hline Min-Max (Median) & $50-133(78)$ & $-1.21 \pm 3.34$ & $\mathrm{t}:-5.381$ & 0.001 \\
\hline Mean \pm SD & $79.79 \pm 13.31$ & & ${ }^{\mathrm{a}} 0.001^{* *}$ & \\
\hline \multicolumn{5}{|l|}{$\mathrm{BMI}\left(\mathrm{kg} / \mathrm{m}^{2}\right)$} \\
\hline Min-Max (Median) & $18.4-43(28.95)$ & $-0.46 \pm 1.54$ & $\mathrm{t}:-4.407$ & 0.001 \\
\hline Mean \pm SD & $29.35 \pm 4.60$ & & ${ }^{\mathrm{a}} 0.001^{* *}$ & \\
\hline \multicolumn{5}{|c|}{ Cycle ergometer test max WATT } \\
\hline Min-Max (Median) & $25-150(75)$ & $15.41 \pm 19.37$ & Z: -9.361 & 0.001 \\
\hline Mean \pm SD & $75.70 \pm 25.00$ & & $\mathrm{~b}_{0.001 * *}$ & \\
\hline \multicolumn{5}{|l|}{ 6MWT (meters) } \\
\hline Min-Max (Median) & $234-650(387)$ & $16.72 \pm 45.42$ & t: 5.486 & 0.001 \\
\hline Mean \pm SD & $392.64 \pm 64.47$ & & ${ }^{\mathrm{a}} 0.001^{* *}$ & \\
\hline
\end{tabular}

aPaired Samples Test; ${ }^{b}$ Wilcoxon Signed Ranks Test; ${ }^{* *} p<0.01$.

Tablo 3. Evaluation of depression and SF-36 HRQoL subscales before and after cardiac rehabilitaion

\begin{tabular}{|c|c|c|c|c|}
\hline \multicolumn{5}{|l|}{ BECK depression } \\
\hline Min-Max (Median) & $0-38(9)$ & $0-37(7)$ & $-3.15 \pm 8.02$ & Z: -5.612 \\
\hline Meant \pm SD & $11.20 \pm 7.93$ & $8.05 \pm 6.25$ & & ${ }^{b} 0.001^{* *}$ \\
\hline \multicolumn{5}{|l|}{ Physical health } \\
\hline Min-Max (Median) & $13-99.25(63)$ & $12.5-98(73.88)$ & $8.08 \pm 20.10$ & t: 5.986 \\
\hline \multicolumn{5}{|l|}{ Mental health } \\
\hline Min-Max (Median) & $15.5-95(62.46)$ & $25.25-99(74.44)$ & $9.27 \pm 19.68$ & t: 7.017 \\
\hline Mean \pm SD & $60.88 \pm 19.34$ & $70.15 \pm 17.29$ & & ${ }^{a} 0.001^{* *}$ \\
\hline
\end{tabular}

aPaired Samples Test; ${ }^{b}$ Wilcoxon Signed Ranks Test; ${ }^{* *} \mathrm{p}<0.01$.

\section{Discussion}

Cardiovascular diseases are responsible for 17.7 million deaths in the world and much more people are living with CVD worldwide which end up CVD to be one of the most mortality and morbidity related diseases ${ }^{[1,2]}$. Type $D$ personality is associated with inflammation and poor prognosis in CVD, so it is accepted as a psychosocial risk factor for $\mathrm{CVD}^{[8]}$. Type $\mathrm{D}$ personality is found to be different percentages in different cardiac patient populations. To our knowledge, this is the first study from Turkey, which investigates Type $D$ personality prevalence for cardiac rehabilitation patients and Type $D$ personality of $C R$ patients found to be $37.4 \%$ in this population. Cross-cultural analysis of Type D personality in 6222 patients worldwide with ischemic heart disease it is found to be between 19 and 44\%, and they concluded this prevalence was lower in Northern (24\%), and Western European and English-speaking (both 27\%) countries as compared to Southern (37\%) and Eastern (35\%) European countries ${ }^{[21]}$. Our findings are concurrent with the literature.

Well planned comprehensive $C R$ is known to increase functional status, HRQoL and decrease mortality and depression scores in CVD ${ }^{[12-14]}$. In one study, Type D personality has been linked to poor HRQoL for patients who had CR for CVD before and after CR ${ }^{[22]}$.

In our study, all patients HRQoL increased in both physical health and mental health subgroups after $C R(p \leq 0.01)$. There was no difference in the increase in HRQoL in Type $D$ patient group and non-Type $D$ group $(p \geq 0.05)$. Type $D$ patients are more prone to heal with social interaction like group therapies, in our comprehensive $C R$ program all exercise sessions are in groups and most of the patients come same day, same hour; thus, it can affect the increase in the HRQoL in our Type D study group.

In one study which focused on Type $D$ personality positive coronary artery disease patients, they compared expended cardiac rehabilitation (increased physical training, stress management, stay at 'Patient Hotel' and cooking sessions) 
Tablo 4. Evaluation of changes before and after rehabilitation according to the presence of type D personality

\begin{tabular}{|c|c|c|c|}
\hline & \multicolumn{2}{|c|}{ Type D } & \multirow[t]{2}{*}{ Test value $p$} \\
\hline & Type $D(+)(n=83)$ & Type D (-) (n=139) & \\
\hline \multicolumn{4}{|l|}{ Weight (kg) } \\
\hline Min-Max (Median) & $-10-13(-1)$ & $-15-8(0)$ & Z: -0.518 \\
\hline Mean \pm SD & $-1.04 \pm 3.44$ & $-1.31 \pm 3.29$ & ${ }^{c} 0.605$ \\
\hline \multicolumn{4}{|l|}{ BMI (kg/m²) } \\
\hline Min-Maks (Median) & $-8.1-4.4(-0.4)$ & $-4,9-6,8(0)$ & Z: -0.682 \\
\hline Mean \pm SD & $-0.53 \pm 1.69$ & $-0.41 \pm 1.45$ & ${ }^{c} 0.496$ \\
\hline \multicolumn{4}{|c|}{ Cycle ergometer test max (WATT) } \\
\hline Min-Maks (Median) & $-25-75(25)$ & $-75-75(25)$ & Z: $-0,753$ \\
\hline Mean \pm SD & $17.07 \pm 17.88$ & $14.42 \pm 20.19$ & ${ }^{c} 0.451$ \\
\hline \multicolumn{4}{|l|}{ 6MWT (Meters) } \\
\hline Min-Maks (Median) & $-118-144(16)$ & $-86-159(18)$ & $Z:-0.812$ \\
\hline Mean \pm SD & $13.69 \pm 45.16$ & $18.53 \pm 45.63$ & ${ }^{c} 0.417$ \\
\hline \multicolumn{4}{|l|}{ BECK depresyon } \\
\hline Min-Maks (Median) & $-33-17(-2)$ & $-23-20(-2)$ & $Z:-0.687$ \\
\hline Mean \pm SD & $-4.01 \pm 10.13$ & $-2.64 \pm 6.43$ & ${ }^{c} 0.492$ \\
\hline \multicolumn{4}{|l|}{ Physical health } \\
\hline Min-Maks (Median) & $-44.5-52.25(8.75)$ & $-65-55.5(5.75)$ & $Z:-0.236$ \\
\hline Mean \pm SD & $7.68 \pm 21.19$ & $8.31 \pm 19.5$ & ${ }^{c} 0.813$ \\
\hline \multicolumn{4}{|l|}{ Mental health } \\
\hline Min-Maks (Median) & $-55-64.5(10.5)$ & $-55.5-58.88(7.66)$ & Z: -0.949 \\
\hline Mean \pm SD & $10.72 \pm 20.54$ & $8.4 \pm 19.18$ & ${ }^{c} 0.343$ \\
\hline
\end{tabular}

'Mann Whitney U Test.

to routine $C R$ and concluded that no significant changes were seen in depression in routine CR group in Type $D$ patients ${ }^{[23]}$. Our study shows that a comprehensive CR program improves $\mathrm{HRQ}$ L, functional status, endurance, and decreases self-estimated Beck Depression scores no matter patients have Type $D$ personality or not. Because the Type $D$ personality is known to be responsible for poor clinical prognosis, impaired psychological and physical health and decreased HRQoL among cardiac patients, these achievements of comprehensive $C R$ on Type $D$ personality patients is really important. More studies can be carried out about this topic which is focused on change in mortality related inflammatory markers with CR on Type D personality positive CAD patients as Type $D$ personality is known to be an inflammatory risk factor. A recent computer tomography study showed that Type $D$ personality is associated with in-stent neoatherosclerosis in coronary patients with the percutaneous coronary intervention ${ }^{[24]}$.

To sum up, our study shows that no matter patients have Type D personality or not, a comprehensive CR program can increase functional status, endurance, HRQoL outcomes and decrease Beck Depression Inventory scores of the $C R$ patients.
Ethics Committee Approval: HNEAH-KAEK 2017/111 dated 13.11.2017 Haydarpaşa Numune Training and Research Hospital Ethics Committee approval was obtained.

Peer-review: Externally peer-reviewed.

Authorship Contributions: Concept: B.B.K.; Design: B.B.K.; Data Collection or Processing: B.B.K., N.Ö.; Analysis or Interpretation: B.B.K.; Literature Search: B.B.K., N.Ö.; Writing: B.B.K.

Conflict of Interest: None declared.

Financial Disclosure: The authors declared that this study received no financial support.

\section{References}

1. WHO. Cardiovascular diseases (CVDs) fact sheet. 2017. doi:Fact sheet $\mathrm{N}^{\circ} 317$.

2. Timmis A, Townsend N, Gale C, Grobbee R, Maniadakis N, Flather M, et al; ESC Scientific Document Group. European Society of Cardiology: Cardiovascular Disease Statistics 2017. Eur Heart J 2018; 39:508-79.

3. Arnett DK, Goodman RA, Halperin JL, Anderson JL, Parekh AK, Zoghbi WA. AHA/ACC/HHS strategies to enhance application of clinical practice guidelines in patients with cardiovascular disease and comorbid conditions. J Am Coll Cardiol. 2014;64:1851-6.

4. Meijer A, Conradi HJ, Bos EH, Thombs BD, van Melle JP, de 
Jonge P. Prognostic association of depression following myocardial infarction with mortality and cardiovascular events: A meta-analysis of 25 years of research. Gen Hosp Psychiatry. 2011;33:203-16.

5. Denollet J. DS14: standard assessment of negative affectivity, social inhibition, and Type D personality, Psychosom Med 2005;67:89-97.

6. Van Dooren FE, Verhey FR, Pouwer F, Schalkwijk CG, Sep SJ, Stehouwer CD, et al. Association of Type D personality with increased vulnerability to depression: Is there a role for inflammation or endothelial dysfunction? - The Maastricht Study. J Affect Disord 2016;189:118-25.

7. Dulfer K, Hazemeijer BA, Van Dijk MR, Van Geuns RJ, Daemen J, Van Domburg RT, et al. Prognostic value of type D personality for 10-year mortality and subjective health status in patients treated with percutaneous coronary intervention. J Psychosom Res. 2015;79:214-21.

8. Pogosova N, Saner H, Pedersen SS, Cupples ME, McGee H, Höfer S, et al; Cardiac Rehabilitation Section of the European Association of Cardiovascular Prevention and Rehabilitation of the European Society of Cardiology. Psychosocial aspects in cardiac rehabilitation: From theory to practice. A position paper from the Cardiac Rehabilitation Section of the European Association of Cardiovascular Prevention and Rehabilitation of the European Society of Cardiology. Eur J Prev Cardiol 2015;22:1290-306.

9. O'Dell KR, Masters KS, Spielmans GI, Maisto SA. Does type-D personality predict outcomes among patients with cardiovascular disease? A meta-analytic review. J Psychosom Res 2011;71:199-206.

10. Leon AS, Franklin BA, Costa F, Balady GJ, Berra KA, Stewart KJ, et al; American Heart Association; Council on Clinical Cardiology (Subcommittee on Exercise, Cardiac Rehabilitation, and Prevention); Council on Nutrition, Physical Activity, and Metabolism (Subcommittee on Physical Activity); American association of Cardiovascular and Pulmonary Rehabilitation. Cardiac rehabilitation and secondary prevention of coronary heart disease: an American Heart Association scientific statement from the Council on Clinical Cardiology (Subcommittee on Exercise, Cardiac Rehabilitation, and Prevention) and the Council on Nutrition, Physical Activity, and Metabolism (Subcommittee on Physical Activity), in collaboration with the American association of Cardiovascular and Pulmonary Rehabilitation. Circulation 2005;111:369-76.

11. Balady GJ, Williams MA, Ades PA, Bittner V, Comoss P, Foody JM,et al; American Heart Association Exercise, Cardiac Rehabilitation, and Prevention Committee, the Council on Clinical Cardiology; American Heart Association Council on Cardiovascular Nursing; American Heart Association Council on Epidemiology and Prevention; American Heart Association Council on Nutrition, Physical Activity, and Metabolism; American Association of Cardiovascular and Pulmonary Rehabilitation. Core components of cardiac rehabilitation/secondary prevention programs: 2007 update: a scientific statement from the American Heart Association Exercise, Cardiac Rehabilitation, and Prevention Committee, the Council on Clinical Cardiology; the Councils on Cardiovascular Nursing, Epidemiology and Prevention, and Nutrition, Physical Activity, and Metabolism; and the American Association of Cardiovascular and Pulmonary Rehabilitation. Circulation 2007;115:2675-82.

12. Anderson L, Thompson DR, Oldridge N, Zwisler A, Rees K, Martin $\mathrm{N}$, et al. Exercise-based cardiac rehabilitation for coronary heart disease. Cochrane Database of Systematic Reviews 2016;1: CD001800.

13. Gellis ZD, Kang-Yi C. Meta-analysis of the effect of cardiac rehabilitation interventions on depression outcomes in adults 64 years of age and older. Am J Cardiol 2012;110:1219-24.

14. Taylor RS, Brown A, Ebrahim S, Jolliffe J, Noorani H, Rees K, et al. Exercise-based rehabilitation for patients with coronary heart disease: systematic review and meta-analysis of randomized controlled trials. Am J Med 2004;116:682-92.

15. Öncü E, Köksoy Vayısoğlu S. D Tipi Kişilik Ölçeğinin Türk Toplumunda Geçerlilik ve Güvenirlilik Çalışması. Ankara Med J 2018; 18: 646-56.

16. Beck AT, Ward CH, Mendelson M, Mock J, Erbaugh J. An inventory for measuring depression. Arch Gen Psychiatry 1961;4:561-71.

17. Hisli N. Beck Depresyon Envanterinin üniversite öğrencileri için geçerlilik ve güvenilirliği. Türk Psikol Derg 1989;7:3-13.

18. Ware JE, Sherbourne CD. The MOS 36-item short-form health status survey (SF-36). 1. Conceptual framework and item selection. Med Care 1992;30:473-83.

19. Koçyiğit H, Aydemir Ö,Fişek G, Ölmez N, Kısa Memiş A. SF36 'nın Türkçe için güvenilirliği ve geçerliliği. İlaç ve tedavi Derg 1999;12:102-6.

20. Bilir Kaya B, İçağasıoğlu A. Reliability and validity of the Turkish version of short form 36 (SF-36) in patients with rheumatoid arthritis. J Surg Med 2018;2:11-6.

21. Kupper N, Pedersen SS, Höfer S, Saner H, Oldridge N, Denollet J. Cross-cultural analysis of type $\mathrm{D}$ (distressed) personality in 6222 patients with ischemic heart disease: a study from the International HeartQoL Project. Int J Cardiol 2013;166:327-33.

22. Sogaro E, Schinina F, Burgisser C, Orso F, Pallante R, Aloi T, et al. Type $D$ personality impairs quality of life, coping and short-term psychological outcome in patients attending an outpatient intensive program of cardiac rehabilitation. Monaldi Arch Chest Dis 2010;74:181-91.

23. Karlsson MR, Edström-Plüss $C$, Held C, Henriksson P, Billing $E$, Wallén NH. Effects of expanded cardiac rehabilitation on psychosocial status in coronary artery disease with focus on type D characteristics. J Behav Med 2007;30:253-61.

24. Ruxue L, Yu H, Gao X, Cao J, Tao H, Yu B, et al. The negative affectivity dimension of Type $D$ personality is associated with in-stent neoatherosclerosis in coronary patients with percutaneous coronary intervention: An optical coherence tomography study, Journal of Psychosomatic Research 2019;120:20-8. 